\title{
Evaluation of Efficacy and Safety of 'AHPL/AYTOP/2014A' in Patients Suffering from Aphthous Ulcers - An Open Label, Randomized, Multi-center, Prospective, Active Controlled, Parallel Group, Clinical Study
}

\author{
Sanjay Nipanikar ${ }^{1, *}$, Narendra Mundhe ${ }^{2}$, Vaishali Deshpande ${ }^{3}$, Nitin Shinde ${ }^{4}$, Mangesh Wakchaoure ${ }^{5}$, Pravin Ghadge \\ 'Ari Healthcare Pvt. Ltd., Pune, Maharashtra, INDIA. \\ ${ }^{2}$ KVTR Ayurvedic College Boradi, Shirpur, Dhule, Maharashtra, INDIA. \\ 3MAM's SS Ayurveda Mahavidyalaya and Sane Guruji Aarogya Kendra, Malwadi, Hadapsar, Pune, Maharashtra, INDIA. \\ ${ }^{4}$ Samhita Yog and Ayurevda Clinic, Hadapsar, Pune, Maharashtra, INDIA. \\ ${ }^{5}$ Moraya Clinic, Alandi road, Bhosri, Pune, Maharashtra, INDIA. \\ ${ }^{6}$ Sant Tukaram Hospital, Maan, Dist-Mulshi, Pune, Maharashtra, INDIA.
}

\begin{abstract}
Background: Aphthous stomatitis is a painful and often inflammatory condition. Objective of the study is to evaluate safety and efficacy of Arimu mouth ulcer gel (AHPL/ AYTOP/2014A) in subjects suffering from aphthous ulcers. Methods: This study compared effect of Arimu mouth ulcer gel (Group I), with sponsors other mouth ulcer gels (Group II, Group III), marketed Ayurvedic formulation (Group IV), and conventional preparation (Group V). Subjects were advised to apply given formulations twice daily for 14 days or till complete healing of ulcer whichever was earlier. Results: A total of 276 subjects completed the study. Statistically significant reduction in the mean pain score (VAS) was observed from first follow up visit and continued till the end of the study in all the groups. If compared, the reduction in the mean pain score was significantly more in Group I than Group II, Group III and Group IV and comparable to that of Group V on Day 3. On other follow up visits, change was comparable between the groups and the difference was not significant. The same trend had been observed
\end{abstract}

for burning sensation. Onset of action was less and duration of action was longer in group I compared to other groups. The number of days required to heal ulcer was less in group I than other groups. Adverse events such as vomiting and fever occurred which were not related to study drugs and did not require discontinuation of the study treatment. Conclusion: Arimu mouth ulcer gel is safe and effective in treating aphthous ulcer.

Key words: : Aphthous stomatitis, VAS score, Onset of action, AHPL/ AYTOP/2014A, Mouth Ulcer, Triamcinolone acetonide.

\section{Correspondence}

Dr. Sanjay Uttamrao Nipanikar

Director - Technical, Ari Healthcare Pvt. Ltd, World Trade Centre Pune, Kharadi-411014, Pune, Maharashtra, INDIA.

Email: sanjay.n@arihealthcare.in

DOI: 10.5530/ijpi.2021.2.42

\section{INTRODUCTION}

Trauma, recurrent aphthous stomatitis, microbial infections, systemic diseases, squamous cell carcinoma and drug therapy are principal causes of oral ulceration. Recurrent aphthous stomatitis (RAS) is the commonest cause amongst these. Studies report that RAS is not infectious. ${ }^{1}$

Currently there is no curative treatment available for RAS. Various topical agents like Corticosteroids, chlorhexidine, Benzydamine, Amlexenox and systemic agents like antimicrobials, corticosteroids, Anti TNF agents, colchicine etc are used for the treatment of aphthous ulcers. They help to alleviate the pain and inflammation in the ulcers but none of them has been proved effective in reducing the recurrence of the attacks. Moreover their long term use is associated with serious adverse reactions. Therefore there is pronounced need of safe as well as effective agent to treat aphthous ulcers that also reduces the frequency of the recurrent attacks. ${ }^{2,3}$

AHPL/AYTOP/2014A gel is a unique polyherbal formulation conceptualized and developed by Ari Healthcare Pvt. Ltd for effective management of Aphthous Ulcers. It contains Piper betel extract, Terminalia chebula extract, Glycyrrhiza glabra extract, Curcuma longa extract and oil of Syzygium aromaticum. All the ingredients of the combination are known to possess antimicrobial and anti-inflammatory activity. ${ }^{4-10}$ Piper betel, Terminalia chebula and Syzygium aromaticum are reported to possess local anesthetic and analgesic activities in various studies. ${ }^{6,8,11}$ Moreover it is known that Curcuma longa and Glycyrrhiza glabra accelerate the wound healing process and are found to be effective in the management of Aphthous stomatitis. ${ }^{9,10,12}$ Looking at the activities of the ingredients present in AHPL/AYTOP/2014A, a hypothesis was postulated that AHPL/AYTOP/2014A gel will be helpful in the management of Aphthous ulcers. Hence, to test this hypothesis, a clinical study titled. "Evaluation of Efficacy and Safety of AHPL/AYTOP/2014A in Patients Suffering from aphthous ulcers" was planned.

\section{METHODS}

\section{Study design}

The study was conducted at 12 sites and was approved by respective Independent and/or Institutional Ethics committee. The CTRI registration number is CTRI/2017/04/008386, dated 21/04/2017.

This was a prospective, multi-center, randomized, open label, active controlled, comparative, parallel group, phase II/III, clinical study conducted in clinically diagnosed aphthous ulcers subjects. Eligible subjects were randomized to one of the five treatment groups as follows: 
Group I- AHPL/AYTOP/2014A (Arimu Mouth Ulcer Gel), Group II AHPL/AYTOP/2014B (Amarantha Mouth Ulcer Gel - Curcuma longa plain), Group III - AHPL/AYTOP/2014C (Ari's Mouth Ulcer Gel Glycyrrhiza glabra + Curcuma longa), Group IV - (Market Preparation I -Saccharum officinarum, Acacia araebica, Acacia farnesiana, Glycyrrhiza glabara, Sassuria lappa, Pluchea lanceolota etc), and Group V - (Market Preparation II -Triamcinolone acetonide).

Subject visited the respective study site for follow-up at visit 1 (day 3), visit 2 (day 7), visit 3 (day 10), and visit 4 (day 14).

\section{Study Participants}

\section{Inclusion Criteria}

Male and female participants of age between 18-60 years with clinically diagnosed aphthous ulcers, minor mouth ulcers that have appeared less than a week prior to the enrollment were included in the study.

\section{Exclusion Criteria}

Participants who were suffering from any other oral or dental disease or active skin diseases, under treatment of ulcers with systemic steroids, vitamins, antibiotics, antihistamines, oral retinoids or immunomodulatory agents within three months before study entry, known hypersensitivity to ingredients used in study drug were excluded from the study. Pregnant or lactating women were also not included in the study.

\section{Study Interventions}

Subjects were advised to apply respective study drug/comparator 4 times a day for 14 days or till complete resolution of ulcers whichever was earlier. The detailed composition of AHPL/AYTOP/2014A is provided in Table 1.

\section{Outcomes}

Primary endpoints: Changes in pain as perceived by patient using VAS scale [time fame: every visit]. Secondary endpoints: Changes in burning sensation as perceived by patient using Likert's scale, number of ulcers, changes in ease of consumption of solid food, and changes in ease of consumption of liquid food were evaluated at each study visit. Changes in percentage of ulcer healing by investigator, assessment of total number of days required to heal ulcer, assessment of ADR/Adverse Events, drug compliance were the secondary endpoints evaluated at each follow up visit. Assessment of onset of action (in seconds) and duration of action (in minutes) and assessment of test formulation (Taste, Consistence, Ease of application and local tolerability) were assessed on baseline visit

\section{Table 1: Composition of AHPL/AYTOP/2014A Gel.}

\begin{tabular}{|c|c|c|c|c|}
\hline $\begin{array}{l}\text { Each gm } \\
\text { Contains }\end{array}$ & Ingredients & Botanical Name & Part used & $\begin{array}{l}\text { Quantity } \\
\%(w / w)\end{array}$ \\
\hline 1 & Nagvalli Extract & Piper betel & Leaves & 1 \\
\hline 2 & Haritaki Extract & $\begin{array}{l}\text { Terminalia } \\
\text { chebula }\end{array}$ & Fruits & 1 \\
\hline 3 & $\begin{array}{l}\text { Yashtimadhu } \\
\text { Extract }\end{array}$ & Glycyrrhiza glabra & $\begin{array}{l}\text { Stem/ } \\
\text { Roots }\end{array}$ & 0.5 \\
\hline 4 & Haridra Extract & Curcuma longa & Rhizomes & 2 \\
\hline 5 & Lavanga oil & $\begin{array}{l}\text { Syzygium } \\
\text { aromaticum }\end{array}$ & Buds & 0.25 \\
\hline 6 & Gel base & --- & --- & $\begin{array}{l}\text { Q.S to } \\
\text { make } \\
100 \%\end{array}$ \\
\hline
\end{tabular}

only. Global assessment for overall change and drug tolerability were assessed by investigator and patients at the end of the study.

\section{Sample Size}

300 (considering 20\% dropout) subjects were planned to enroll to get 250 (50 per group) completers at the end of the study. Those 300 subjects provided $80 \%$ power.

\section{Randomization}

As per computer generated randomization list, subjects were randomized to one of the five study groups by using a stratified block randomization and site was considered as the stratification factor.

\section{Statistical Method}

Summary statistics (n, mean, standard deviation, range) were presented for continuous variables, and counts and percentages were presented for categorical variables. Primary efficacy end point was analyzed by using analysis of covariance with Kruskal Wallis test with an analysis of variance with factors of treatment and investigational site. For significant changes, Post hoc test (Dunnett Test) was estimated to assess the difference between groups. The secondary efficacy parameters were analyzed between and within groups by using Chi square test, analysis of variance and Bonferroni Test. The proportion of AEs and assessment of tolerability between groups were estimated by Chi Square test. All the laboratory data were analyzed by using student analysis of variance. All the values were reported based on two-sided test of significance and all the statistical tests were interpreted at $5 \%$ level of significance level.

\section{RESULTS}

A total of 284 subjects were randomized across the treatment groups of which 276 subjects completed the study. The details are presented in Table 2. No significant difference between the groups with respect to demographic characteristics such as age, sex, and gender was observed.

At the end of Day 3, the mean pain score assessed on VAS scale showed significant reduction in all the groups from baseline visit. If compared between the groups, change was significantly better among Group I than Group II, Group III and Group IV and comparable to Group V and the difference was not significant. On day 10, no patient from group I had pain and the mean pain score reduced further in other groups as well. On day 14, pain was completely subsided in patients of group I, IV and V. The mean pain score reduced further in group II and III. If compared between the groups, the difference was not significant. The details are given in following Table 3 .

On day 3, the mean score of burning sensation showed significant reduction in all the groups from baseline visit. If compared between groups, change was significantly better among Group I than Group II, Group III and Group IV and comparable to Group V and the difference was not significant. On day 10 , no patient from group I and V had burning sensation and the mean score of burning sensation reduced

\section{Table 2: Subject disposition.}

\begin{tabular}{cccccc} 
Parameters & $\begin{array}{c}\text { Group } \\
\text { I }\end{array}$ & $\begin{array}{c}\text { Group } \\
\text { II }\end{array}$ & $\begin{array}{c}\text { Group } \\
\text { III }\end{array}$ & $\begin{array}{c}\text { Group } \\
\text { IV }\end{array}$ & $\begin{array}{c}\text { Group } \\
\text { V }\end{array}$ \\
\hline $\begin{array}{c}\text { No. of cases enrolled } \\
57\end{array}$ & 60 & 55 & 60 & 52 \\
No. of cases dropped out & 03 & 01 & 01 & 02 & 01 \\
No. of cases Analyzed & 54 & 59 & 54 & 58 & 51 \\
$\begin{array}{c}\text { No. of cases analyzed for } \\
\text { safety }\end{array}$ & 57 & 60 & 55 & 60 & 52 \\
\hline
\end{tabular}


further in other groups also. On day 14, the mean score of burning sensation was completely subsided in patients of group I, IV and V. The mean score of burning sensation reduced further in group II and III. If compared between the groups, the difference was not significant. The details are given in following Table 4.

On day 3, the mean number of ulcers reduced significantly in all the groups. If compared between the groups, the change was significantly better among Group I than Group III and Group IV and comparable to Group II and Group V and the difference was not significant. On day 10, there were no ulcers in group I and V, while the mean number of ulcers reduced in other groups. On day 14 , there were no ulcers in any of the patients. The details are presented in Figure 1.

On day 3 , the mean percentage of healing of index ulcer was $87.41 \pm$ $20.76,73.90 \pm 28.16,75.00 \pm 28.86,71.40 \pm 28.94$ and $74.90 \pm 30.88$ among group I, II, III, IV and V respectively. If compared between the groups, the change was significantly better in Group I than Group II, Group III, Group IV and Group V. On day 14, the index ulcer was completely healed in group I, II, III and IV and the mean percentage healing of index ulcer in group $\mathrm{V}$ was $99.71 \pm 01.55$. If compared between the groups, the difference was statistically insignificant. The details are presented in Figure 2.

The mean time required for ulcer healing was $4.70 \pm 2.34$ days in Group I, $5.75 \pm 2.09$ days in group II, $5.65 \pm 2.89$ days in group III, $6.00 \pm 2.44$ days in group IV and $5.39 \pm 2.39$ days in group V. If compared between the groups, the difference was not statistically significant.

The mean score of ease of consumption of solid food on baseline visit was $2.61 \pm 0.98,2.51 \pm 1.06,2.61 \pm 1.07,2.69 \pm 0.96$ and $2.59 \pm 0.98$ in group I, II, III, IV and V respectively. The mean score of ease of consumption of solid food reduced significantly in all the groups on day 3. If compared between the groups, the reduction in the mean score of consumption of solid food was significantly better in group I than rest of the groups. On day 10 , no difficulty in consumption of solid food in group I patients

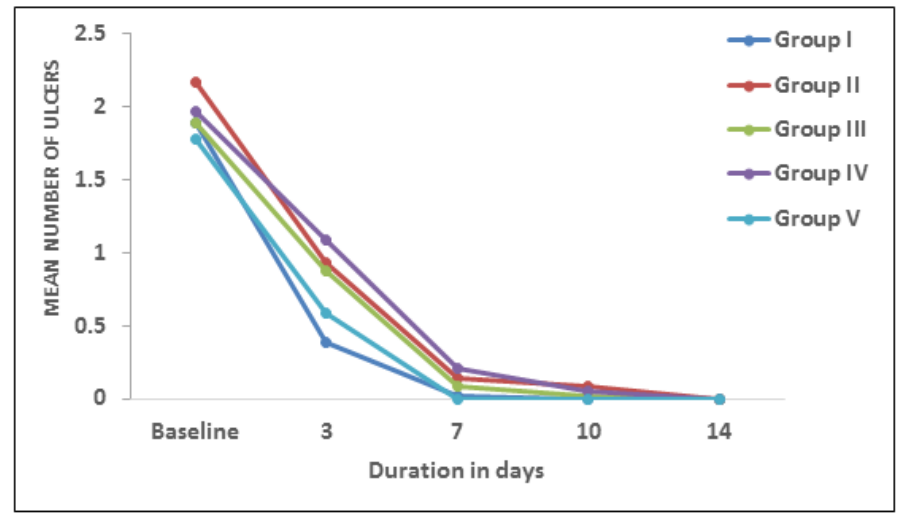

Figure 1: Changes in mean number of ulcers between the groups.

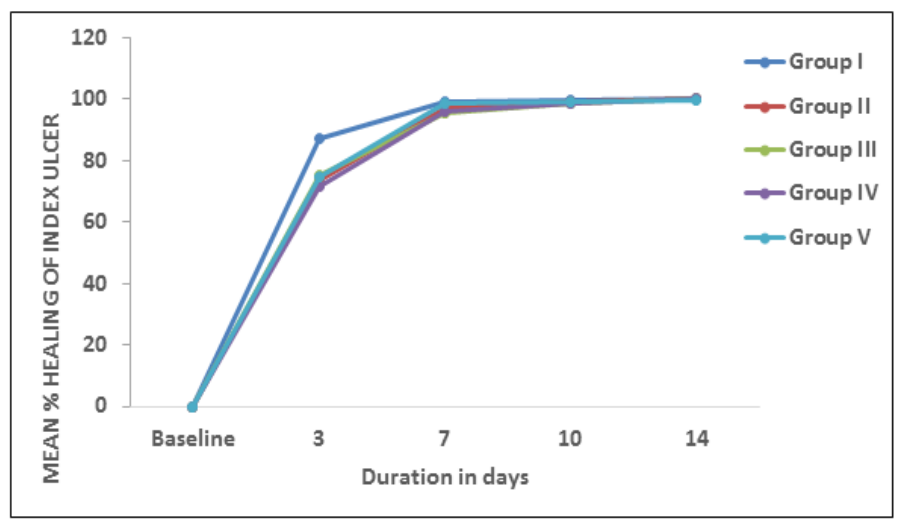

Figure 2: Comparison of changes in mean \% healing of index ulcer between the groups.

Table 3: Pain score ( $\bar{x} \pm$ SD) assessed on VAS.

\begin{tabular}{|c|c|c|c|c|c|}
\hline $\begin{array}{c}\text { Duration } \\
\text { (Days) }\end{array}$ & $\begin{array}{l}\text { Group I } \\
(N=54)\end{array}$ & $\begin{array}{l}\text { Group II } \\
(N=59)\end{array}$ & $\begin{array}{l}\text { Group III } \\
(N=54)\end{array}$ & $\begin{array}{l}\text { Group IV } \\
(N=58)\end{array}$ & $\begin{array}{l}\text { Group V } \\
(N=51)\end{array}$ \\
\hline Baseline & $65.00 \pm 26.97$ & $64.41 \pm 24.72$ & $66.67 \pm 24.11$ & $65.00 \pm 24.44$ & $64.90 \pm 22.75$ \\
\hline 3 & $09.91 \pm 18.03$ & $20.42 \pm 24.57$ & $22.96 \pm 25.96$ & $22.24 \pm 24.43$ & $15.29 \pm 20.43$ \\
\hline 7 & $01.20 \pm 04.65$ & $03.22 \pm 13.75$ & $02.31 \pm 09.15$ & $02.59 \pm 09.83$ & $01.76 \pm 08.08$ \\
\hline 10 & $00.00 \pm 00.00$ & $01.19 \pm 06.46$ & $01.11 \pm 05.72$ & $01.21 \pm 07.03$ & $00.98 \pm 05.00$ \\
\hline 14 & $00.00 \pm 00.00$ & $00.34 \pm 01.83$ & $00.19 \pm 01.36$ & $00.00 \pm 00.00$ & $00.00 \pm 00.00$ \\
\hline $\begin{array}{c}\text { Mean diff } \\
(\mathrm{B}-\mathrm{D} 3)(P \\
\text { value })\end{array}$ & $\begin{array}{c}{ }^{*}-55.09 \pm 27.17 \\
(0.001)\end{array}$ & $\begin{array}{c}\varrho^{*}-43.98 \pm 24.84 \\
(0.001)\end{array}$ & $\begin{array}{c}@^{*}-43.70 \pm 24.82 \\
(0.001)\end{array}$ & $\begin{array}{c}\varrho^{*}-42.76 \pm 23.00 \\
(0.001)\end{array}$ & $\begin{array}{c}*-49.61 \pm 23.66 \\
(0.001)\end{array}$ \\
\hline $\begin{array}{c}\text { Mean diff } \\
(\mathrm{B}-\mathrm{D} 7)(P \\
\text { value })\end{array}$ & $\begin{array}{c}*-63.80 \pm 26.40 \\
(0.001)\end{array}$ & $\begin{array}{c}{ }^{*}-61.19 \pm 26.27 \\
(0.001)\end{array}$ & $\begin{array}{c}{ }^{*}-64.35 \pm 25.25 \\
(0.001)\end{array}$ & $\begin{array}{c}*-62.41 \pm 24.66 \\
(0.001)\end{array}$ & $\begin{array}{c}{ }^{*}-63.14 \pm 24.70 \\
(0.001)\end{array}$ \\
\hline $\begin{array}{c}\text { Mean diff } \\
(\mathrm{B}-\mathrm{D} 10)(P \\
\text { value })\end{array}$ & $\begin{array}{c}*-65.00 \pm 26.97 \\
(0.001)\end{array}$ & $\begin{array}{c}{ }^{*}-63.22 \pm 24.31 \\
(0.001)\end{array}$ & $\begin{array}{c}{ }^{*}-65.56 \pm 24.55 \\
(0.001)\end{array}$ & $\begin{array}{c}{ }^{*}-63.79 \pm 24.70 \\
(0.001)\end{array}$ & $\begin{array}{c}{ }^{*}-63.92 \pm 22.99 \\
(0.001)\end{array}$ \\
\hline $\begin{array}{c}\text { Mean diff } \\
(B-D 14)(P \\
\text { value })\end{array}$ & $\begin{array}{c}*-65.00 \pm 26.97 \\
(0.001)\end{array}$ & $\begin{array}{c}{ }^{*}-64.07 \pm 24.43 \\
(0.001)\end{array}$ & $\begin{array}{c}{ }^{*}-66.48 \pm 23.96 \\
(0.001)\end{array}$ & $\begin{array}{c}{ }^{*}-65.00 \pm 24.44 \\
(0.001)\end{array}$ & $\begin{array}{c}{ }^{*}-64.90 \pm 22.75 \\
(0.001)\end{array}$ \\
\hline
\end{tabular}

Analysis was done by ANOVA (Kruskal Wallis Test), * Significant, @ - between groups 
Table 4: Burning sensation as perceived by patient using Likert's scale (Mean + SD).

\begin{tabular}{|c|c|c|c|c|c|}
\hline $\begin{array}{c}\text { Duration } \\
\text { (Days) }\end{array}$ & $\begin{array}{l}\text { Group I } \\
(N=54)\end{array}$ & $\begin{array}{l}\text { Group II } \\
(N=59)\end{array}$ & $\begin{array}{l}\text { Group III } \\
(N=54)\end{array}$ & $\begin{array}{l}\text { Group IV } \\
(N=58)\end{array}$ & $\begin{array}{l}\text { Group V } \\
(N=51)\end{array}$ \\
\hline $\begin{array}{c}\text { Baseline } \\
\text { Visit }\end{array}$ & $2.78 \pm 0.92$ & $2.56 \pm 0.93$ & $2.63 \pm 1.03$ & $2.69 \pm 0.99$ & $2.73 \pm 1.02$ \\
\hline 3 & $0.43 \pm 0.81$ & $0.80 \pm 0.96$ & $0.89 \pm 1.02$ & $0.97 \pm 0.99$ & $0.67 \pm 0.89$ \\
\hline 7 & $0.06 \pm 0.23$ & $0.19 \pm 0.63$ & $0.11 \pm 0.42$ & $0.14 \pm 0.48$ & $0.04 \pm 0.20$ \\
\hline 10 & $0.00 \pm 0.00$ & $0.03 \pm 0.18$ & $0.04 \pm 0.19$ & $0.02 \pm 0.13$ & $0.00 \pm 0.00$ \\
\hline 14 & $0.00 \pm 0.00$ & $0.02 \pm 0.13$ & $0.02 \pm 0.14$ & $0.00 \pm 0.00$ & $0.00 \pm 0.00$ \\
\hline $\begin{array}{l}\text { Mean diff (B - } \\
\text { D3) ( } P \text { value })\end{array}$ & $\begin{array}{c}{ }^{*}-2.35 \pm 0.99 \\
(0.001)\end{array}$ & $\begin{array}{c}@^{*}-1.76 \pm 1.15 \\
(0.001)\end{array}$ & $\begin{array}{c}@^{*}-1.74 \pm 0.91 \\
(0.001)\end{array}$ & $\begin{array}{c}@^{*}-1.72 \pm 0.87 \\
(0.001)\end{array}$ & $\begin{array}{c}{ }^{*}-2.06 \pm 0.88 \\
(0.001)\end{array}$ \\
\hline $\begin{array}{l}\text { Mean diff (B - } \\
\text { D7) ( } P \text { value })\end{array}$ & $\begin{array}{c}{ }^{*}-2.72 \pm 0.94 \\
(0.001)\end{array}$ & $\begin{array}{c}*-2.37 \pm 1.16 \\
(0.001)\end{array}$ & $\begin{array}{c}*-2.52 \pm 1.08 \\
(0.001)\end{array}$ & $\begin{array}{c}*-2.55 \pm 0.99 \\
(0.001)\end{array}$ & $\begin{array}{c}*-2.69 \pm 1.05 \\
(0.001)\end{array}$ \\
\hline $\begin{array}{l}\text { Mean diff (B - } \\
\text { D10) (P value) }\end{array}$ & $\begin{array}{c}{ }^{*}-2.78 \pm 0.92 \\
(0.001)\end{array}$ & $\begin{array}{c}*-2.53 \pm 0.95 \\
(0.001)\end{array}$ & $\begin{array}{c}*-2.59 \pm 1.04 \\
(0.001)\end{array}$ & $\begin{array}{c}*-2.67 \pm 1.00 \\
(0.001)\end{array}$ & $\begin{array}{c}*-2.73 \pm 1.02 \\
(0.001)\end{array}$ \\
\hline $\begin{array}{l}\text { Mean diff (B - } \\
\text { D14) ( } P \text { value })\end{array}$ & $\begin{array}{c}*-2.78 \pm 0.92 \\
(0.001)\end{array}$ & $\begin{array}{c}*-2.54 \pm 0.93 \\
(0.001)\end{array}$ & $\begin{array}{c}*-2.61 \pm 1.05 \\
(0.001)\end{array}$ & $\begin{array}{c}*-2.69 \pm 0.99 \\
(0.001)\end{array}$ & $\begin{array}{c}*-2.73 \pm 1.02 \\
(0.001)\end{array}$ \\
\hline
\end{tabular}

Analysis was done by ANOVA (Kruskal Wallis Test), ${ }^{\star}$ - Significant, @ - between groups

was observed, while the mean score of ease of consumption of solid food reduced further in all the groups. On day 14, no difficulty in consumption of solid food in almost all the groups was observed. The details are presented in Figure 3.

The mean score of ease of consumption of liquid food on baseline visit was $2.26 \pm 1.17,2.17 \pm 1.07,2.09 \pm 1.20,2.19 \pm 1.05$ and $1.96 \pm 1.11$ in group I, II, III, IV and V respectively. The mean score of ease of consumption of liquid food reduced significantly in all the groups on day 3. If compared between the groups, the reduction in the mean score of consumption of liquid food was significantly better in group I and II than rest of the groups. On day 10, no difficulty in consumption of liquid food in group I, III, IV and V patients was observed, while the mean score of ease of consumption of liquid food reduced further in group II patients. If compared between the groups, the difference was not significant. On day 14, no difficulty in consumption of liquid food in all the groups was observed. The details are presented in Figure 4.

The mean time required for onset of action of drugs was $69.63 \pm 091.77$ sec, $91.93 \pm 132.13 \mathrm{sec}, 88.80 \pm 127.26 \mathrm{sec}, 84.19 \pm 071.71 \mathrm{sec}$ and 83.51 $\pm 172.36 \mathrm{sec}$ in patients of group I, II, III, IV and V respectively. If compared between the groups the time required for onset of action of drug was less in group I than rest of the groups, but the differences was statistically insignificant.

The mean time of duration of action of drugs was $78.46 \pm 62.22 \mathrm{~min}, 62.90$ $\pm 54.65 \mathrm{~min}, 60.94 \pm 41.29 \mathrm{~min}, 60.52 \pm 39.84 \mathrm{~min}$ and $71.10 \pm 44.69 \mathrm{~min}$ in patients of group I, II, III, IV and V respectively. If compared between the groups the time of duration of action of drug was more in group I than rest of the groups, but the differences was statistically insignificant. When compared between the groups, significantly excellent consistency and taste was reported in group I than rest of the groups. Ease of application (very easy) of study drug was better (56.6\%) in treatment Group I than other treatment groups, however, the difference was not significant. All the study drugs were well tolerated, when compared between the groups, the difference was not significant.

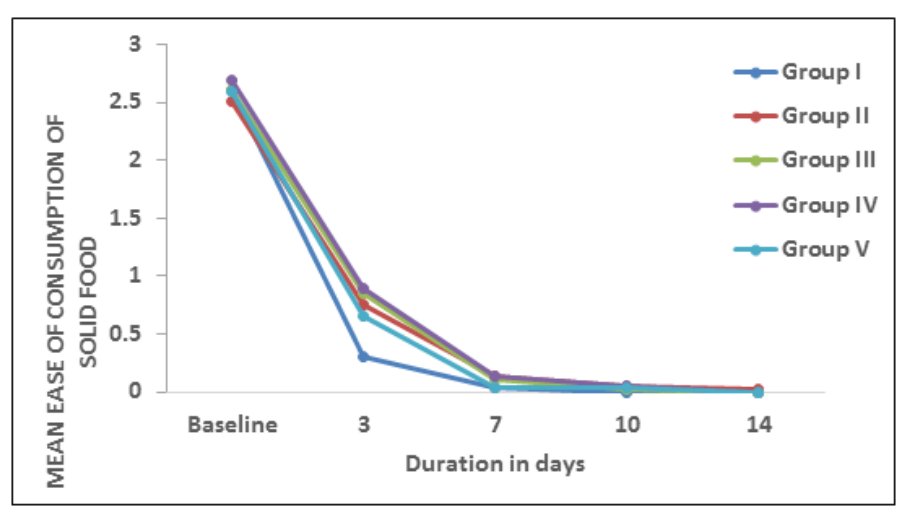

Figure 3: Comparison of changes in the mean score of ease of consumption of solid food between the groups.

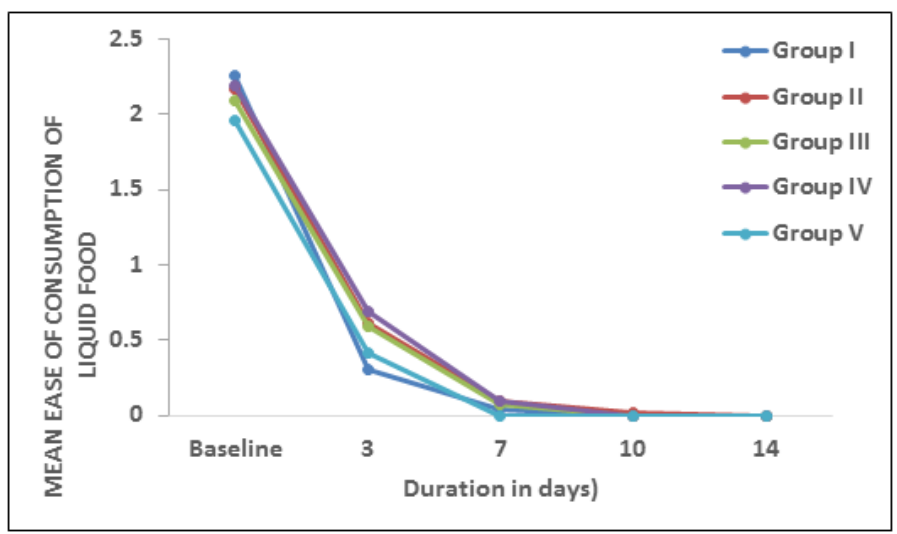

Figure 4: Comparison of changes in the mean score of ease of consumption of liquid food between the groups. 
As per investigator's assessment, 98.1\%, 88.1\%, 88.5\%, 92.7\%, and $94.1 \%$ and subjects of group I, II, III, IV and V had excellent to good improvement respectively. As per the investigator's evaluation, 98.1\%, $98.3 \%, 100 \%, 98.2 \%$, and $100 \%$ subjects of group I, II, III, IV and V reported to have excellent drug tolerability.

One subject from group II had vomiting (mild in intensity) during the study period. The vomiting disappeared without any treatment and the study treatment was not stopped. As per investigator's opinion the event was possibly related to the study drug. Another subject from group III had mild fever, which was disappeared without any treatment and the study treatment was not stopped. As per investigator's opinion the event was remotely related to the study drug. No serious adverse event was reported in any of the subjects during the study period.

No significant change from baseline to end of therapy in values of any of the vital signs (pulse rate, body temperature, respiratory rate, systolic and diastolic blood pressure) and body weight was observed across the treatment groups.

\section{DISCUSSION}

Pain is the most bothering symptoms of aphthous ulcer. On day 3 of treatment, statistically significant reduction in pain was observed in all the study groups. When compared between the groups, the reduction in pain was significantly better in group I than group II, III and IV and comparable to group $\mathrm{V}$, suggesting better pain relieving action of AHPL/ AYTOP/2014A in comparison to group II, III and IV. Burning sensation at ulcer is the second most bothering symptom of aphthous ulcer. The statistically significant reduction in burning sensation was also observed on day 3 of treatment in all study groups. When compared between the groups, the reduction in burning sensation was significantly better in group I than group II, III and IV and comparable to group V, suggesting better burning sensation relieving action of AHPL/AYTOP/2014A in comparison to group II, III and IV. Since pain and burning sensation were relieved effectively, there was statistically significant improvement in ease of consumption of solid and liquid food on day 3 of treatment in all the groups. When compared between the groups, the improvement in consumption of solid food was significantly better in group I than rest of the groups. Also when compared between the groups, the improvement in consumption of liquid food was significantly more in group I than group III, IV and V and comparable to group II.

Almost all the ingredients present in AHPL/AYTOP/2014A possess antiinflammatory activity. ${ }^{4-10}$ Piper betle possesses potent local anesthetic activity by both surface and infiltration techniques. ${ }^{6}$ Also Terminalia chebula and Syzygium aromaticum are well known for their significant analgesic and local anesthetic activities. ${ }^{8} 11$ The synergestic activities of these ingredients could have contributed towards reduction of pain and burning sensation effectively over other medications under study.

Number of days required to heal the ulcers was less in group I (4.70 days) than rest of the groups. When compared between the groups, the difference was not statistically significant. Also the percentage of healing of index ulcer was significantly better in group I than rest of the groups on day 3 of treatment suggesting better and faster healing by AHPL/AYTOP/2014A in comparison to other study drugs. AHPL/ AYTOP/2014A consists of Curcuma longa (standardized to not less than 95\% curcuminoids) and Glycyrrhiza glabra, which are potent, wound healing agents. ${ }^{912}$ Piper betle, Terminalia chebula, Glycyrrhiza glabra, Syzygium aromaticum, and Curcuma longa possess anti-microbial activity. Because of the synergestic activity of the ingredients present in the formulation, AHPL/AYTOP/2014A was effective in terms of faster healing of ulcer than other study medications., ${ }^{4,7,9,11,12}$
The onset of action of drug was less $(69.63 \mathrm{sec})$ in group I than other study drugs. When compared between the groups the difference was not statistically significant. Also the duration of action of drug was more (78.46 min) in group I than rest of the groups. When compared between the groups, the difference was not statistically significant.

Subjects from group I reported statistically significant better consistency and taste of the study drug than rest of the study drugs. When local tolerability and ease of application of study drugs was compared between the groups, no statistically significant difference was observed. As the ulcers healed between 4.7 to 6 days in all the study groups, no statistical significant difference was noted in global evaluation of overall improvement assessed by physician and subjects at the end of the study. Also all the study drugs were well tolerated by the subjects. One subject from group II had mild vomiting that disappeared without any treatment. As per investigator's opinion the event was possibly related to the study drug. Another subject from group III had mild fever, which was disappeared without any treatment. As per investigator's opinion the event was remotely related to the study drug. No serious adverse event was reported in any subject during the study period. No post treatment significant change in pulse rate, body temperature, body weight, respiratory rate, systolic and diastolic blood pressure was observed in any groups suggesting safety of all the study drugs.

\section{CONCLUSION}

It can be concluded that, all the study drugs are safe and effective in treating aphthous ulcers. AHPL/AYTOP/2014A was superior to AHPL/AYTOP/2014B, AHPL/AYTOP/2014C, Market Preparation I (Ayurvedic) and comparable to Market Preparation II (Conventional) in terms of relieving pain and burning sensation. AHPL/AYTOP/2014A also provides significant relief from discomfort caused by mouth ulcer during consumption of solid and liquid food. The onset of action was faster and duration of action was longer in AHPL/AYTOP/2014A than rest of the study drugs. Also number of days required to heal the ulcers was less in AHPL/AYTOP/2014A than rest of the study drugs. Thus AHPL/AYTOP/2014A is safe and effective in treating aphthous ulcer.

\section{ACKNOWLEDGEMENT}

The authors sincerely thank all trial sites staff for their contribution in the conduct of the present clinical study. The authors also sincerely thank Mr. Kailas Gandewar, Biostatistician, Soham Consultancy, Dadar Mumbai for his kind help in sample size calculation and data analysis. Authors also thank Mr. Unmesh Keshwar, Manager- Analytical, for his support in publication. Authors are extremely grateful to Mr. Sanjeevan Kanjilal (Managing Director) and Dr. Anisha Kanjilal (Director) of Ari Healthcare Pvt. Ltd. for providing all the research facilities, guidance, courage and moral support.

\section{CONFLICT OF INTEREST}

The authors declare that there is no conflict of interest.

\section{ABBREVIATIONS}

VAS: Visual Analogue Scale; RAS: Recurrent aphthous stomatitis; CTRI: Clinical Trial Registry of India; SD: standard Deviation; ADR: Adverse Drug Reaction; ANOVA: Analysis of variance; TNF: Tumour necrosis factor; AE: Adverse events; Sec: Seconds.

\section{REFERENCES}

\footnotetext{
1. Field EA, Allan RB. Review article: Oral ulceration etiopathogenesis, clinical diagnosis and management in the gastrointestinal clinic. Aliment PharmacolTher. 2003;18(10):949-62
} 
2. Jurge S, Kuffer R, Scully C, Porter SR. Mucosal disease series. Number VI. Recurrent aphthous stomatitis. Oral Dis. 2006;12(1):1-21.

3. Scully C, Gorsky M, Lozada-Nur F. The diagnosis and management of recurrent aphthous stomatitis: A consensus approach. J Am Dent Assoc. 2003;134(2):200-7.

4. Chakraborty D, Shah B. Antimicrobial, anti-oxidative and antihemolytic activity of Piper betel leaf extracts. Int J Pharm Pharm Sci. 2011;3(3):192-9.

5. Dwivedi V, Tripathi S. Review study on potential activity of Piper betle. J Pharmacogn Phytochem. 2014;3(4):93-8.

6. Krishnakumar S, Geetha VS, Kuruvilla A. Determination of local anesthetic action of Betel leaf extract alone and with Betel nut using infiltration and surface anesthesia. J Nat Remedies. 2001;1(1):28-32.

7. Gupta PC. Biological and pharmacological properties of Terminalia chebula retz. (haritaki): An overview. Int J Pharm Pharm Sci. 2012;4(3):62-8.

8. Jayasree T, Nagesh CH, Prakash M, Shankar J, Sekhar CN. Evaluation of surface anaesthetic activity of alcoholic extract of fruit of Terminalia chebula on the cornea of albino rabbits. Bull Pharm Med Sci. 2013;1(1):16-9.

9. Zaki AA, El-Bakry MH, Fahmy AA. Effect of Licorice on Wound Healing In Rabbits. Egypt J Hosp Med. 2005;20(1):58-65.

10. Oloumi MM, Derakhshanfar A, Nikpoor A. Healing potential of liquorice root extract on dermal wounds in rats. J Vet Res, 2007;62(4):147-54.

11. Dhinahar S, Lakshmi T. Role of botanicals as antimicrobial agents in management of dental infections: A review. Int J Pharma Bio Sci. 2011;2(4):690-704.

12. Farid RM. A focus on curcumin local application in oral diseases management: Mini Review. IOSR J Pharm. 2016;6(1):30-40.

Article History: Submission Date : 08-02-2021: Revised Date : 20-05-2021; Acceptance Date : 18-06-2021.

Cite this article: Nipanikar S, Mundhe N, Deshpande V, Shinde N, Wakchaoure M, Ghadge P. Evaluation of Efficacy and Safety of 'AHPL/AYTOP/2014A' in Patients Suffering from Aphthous Ulcers - An Open Label, Randomized, Multi-center, Prospective, Active Controlled, Parallel Group, Clinical Study. Int. J. Pharm. Investigation, 2021;11(2):238-43. 